\title{
Avaliação do envelhecimento a curto prazo nas propriedades reológicas de ligantes asfálticos modificados com resíduo da mineração de cobre sulfetado
}

Ricardo Bentes Kato $^{1 *}$ (1)

\section{Resumo}

O envelhecimento dos ligantes asfálticos altera as propriedades das misturas asfálticas, e provoca alterações reológicas, porém nas especificações brasileiras alguns parâmetros levam em consideração o envelhecimento do ligante e seus efeito sobre as propriedades reológicas dos materiais. $\mathrm{O}$ objetivo deste artigo é identificar as alterações reológicas devido ao envelhecimento a curto prazo em ligantes asfálticos aditivados com resíduo da mineração do cobre sulfetado, pois vislumbra-se a adição do resíduo ao ligante asfáltico na região amazônica em função do grande volume de produção deste tipo de rejeito. Os resultados mostraram diferenças insignificantes das amostras com e sem resíduo, inclusive para ensaio de MSCR que resultou em ligantes resistentes ao tráfego padrão, podendo suportar volume de 10 milhões de eixos padrões durante a vida de projeto.

Palavras-chave: Envelhecimento a curto prazo; Resíduo; Ligantes asfálticos.

\section{Study of resistance to drainage in asfalic concrete against temperature variation and incorporation of copper mining residue}

\begin{abstract}
The aging of the asphalt binders alters properties of the asphalt mixtures, besides causes rheological changes, however the Brazilian specifications still do not take into account this effect on the rheological properties of the materials. The objective of this paper is to identify the rheological changes due to the short-term aging of asphalt binders added with the sulfide copper mine tailing, in order to verify the possibility of its use in asphalt mixtures of Amazon region due to the fact of wide production of copper mine tailing. The results showed insignificant differences of the samples with and without residue, including for the MSCR test that resulted in asphalt binders resistant to standard traffic, allowing support a volume of 10 million standard axes during the project life.
\end{abstract}

Keywords: Short-term aging; Copper mine tailing; Asphalt binders.

\section{Introdução}

O envelhecimento no ligante asfáltico envolve um conjunto de processos físico-químicos complexos que ocorrem durante a utilização. É geralmente dividido em envelhecimento a curto prazo, que ocorre durante a estocagem, usinagem, transporte, compactação e envelhecimento. A longo prazo o envelhecimento do ligante é no decorrer da vida de serviço. Define-se envelhecimento como modificações ocorridas no ligante asfáltico em decorrência da exposição às condições ambientais, que podem aumentar a rigidez, assim como deixa-la mais susceptível à desagregação.

As principais formas de envelhecimento são a oxidação, a exposição a luz e a redução de constituintes oleosos devido a absorção dos agregados. A oxidação se dá pela reação do ligante com o oxigênio, que provoca aumento da viscosidade do ligante devido a maior interação das forças moleculares (polaridade dos produtos oxigenados), fato observado nos processos de usinagem, estocagem, manuseio e aplicação da mistura, alterando suas características químicas e reológicas [1].

A ação dos raios ultravioletas afeta a fina camada de ligante (cerca de $2 \mu \mathrm{m}$ ) que envolve os agregados. Devido a exposição da superfície do pavimento ao ar, o envelhecimento ou oxidação do ligante ocorre em taxas diferentes ao longo da profundidade da camada. Esta exposição produz compostos solúveis em água, tendo assim um efeito erosivo

${ }^{I}$ Universidade Federal do Pará - UFPA, Belém, PA, Brasil.

*Autor correspondente: r.kato@hotmail.com 
na superfície exposta quando da presença de chuva, além da presença de trincas [2].

A temperatura e a oxidação são os principais fatores que influenciam o processo de envelhecimento das misturas asfálticas, causando principalmente a redução da vida de fadiga do pavimento, que deve ser considerado no dimensionamento das misturas [3].

A oxidação é a principal forma de envelhecimento, sendo que sua taxa de envelhecimento dobra a cada $10^{\circ} \mathrm{C}$ a partir dos $100^{\circ} \mathrm{C}$. Este efeito é representado fisicamente pelo aumento da consistência do CAP, tornando-o mais quebradiço, menos dúctil e menos elástico [4].

Em laboratório é possível simular o envelhecimento dos ligantes em campo. A técnica de Rolling Thin Film Oven Test (RTFOT) (ASTM D 2872-88) simula o envelhecimento do ligante asfáltico durante processo de usinagem, por isso o ensaio é realizado a altas temperaturas e na presença de oxigênio $[5,6]$.

Por outro lado, a técnica conhecida como Pressure Aging Vessel (PAV), foi desenvolvida pelo Strategic Highway Research Program (SHRP), visando simular o envelhecimento do ligante durante sua vida em serviço, sendo realizado sob alta pressão de ar, temperatura da ordem de $100^{\circ} \mathrm{C}$ por vinte horas. Recomenda-se a execução do PAV após o RTFOT chamando-se esta sequência RTFOT + PAV de envelhecimento clássico, podendo simular as mesmas características de um ligante de 3 a 6 anos de uso. Após envelhecido, o ligante pode ser submetido aos ensaios empíricos tradicionais, ou a ensaios mais elaborados para analisar sua reologia, em reômetros, como o DSR (Reômetro de Cisalhamento Dinâmico), comparando os resultados das amostras antes e após envelhecimento $[7,8]$.

Este artigo faz parte de uma pesquisa maior, onde estuda-se adicionar o resíduo da mineração do cobre sulfetado ao concreto asfáltico. Derivado do grego "aescyprium", sendo posteriormente conhecido como "cuprum", dureza 2,5 a 3,0 , ponto de fusão $1.023^{\circ} \mathrm{C}$. O que o torna valioso para a indústria é o fato de ser um ótimo condutor de calor e eletricidade. Outras propriedades importantes são sua elevada resistência à tensão física e à corrosão, além de propriedade não magnética e a facilidade na formação de ligas com outros metais. Considera-se como cobre o metal que possua $99,85 \%$ ou mais do elemento cobre, ou no mínimo $97,5 \%$ em massa de cobre $[7,8]$.

As jazidas de cobre são geralmente de grandes dimensões e baixos teores, gerando grande quantidade de resíduo proveniente de sua mineração. Em minas de lavra subterrânea, o teor de corte não deve ficar abaixo de $1 \%$ de cobre, e nos de pequeno porte, não deve ser inferior a $3 \%$. Em lavra a céu aberto, o teor mínimo pode atingir $0,5 \%$ de Cobre. O material utilizado nesta pesquisa é proveniente de uma jazida que tem previsão de geração de 11 milhões de toneladas ao ano de resíduo $[7,8]$.

No final dos anos 70 , foram realizadas pesquisas sobre a possibilidade do uso de geopolímeros modificado com resíduo de cobre na construção rodoviária. Os resultados do estudo mostraram que o resíduo de cobre tem excelentes propriedades e pode ser utilizado nos pavimentos rodoviário. A pesquisa com o resíduo de cobre foi transferida para sua aplicação em tecnologia do concreto com cimento Portland, e mostraram que o resíduo de cobre pode ser usado como aditivo de concreto Portland [9-11].

Pesquisas do RCS em argamassas para a indústria de construção civil, a fim de reduzir o impacto sobre o meio ambiente na Região de Atacama, no Chile. A avaliação foi realizada por meio de uma comparação técnica entre argamassas preparadas com areia convencional e o RCS. A análise química quantitativa do RCS, indicou a presença dos mesmos compostos químicos presentes na areia da região do Atacama, Chile. O resultado mostrou ser inerte o RCS [12].

O objetivo deste artigo é identificar as alterações reológicas devido ao envelhecimento a curto prazo em ligantes asfálticos aditivados com resíduo da mineração do cobre sulfetado, pois vislumbra-se a adição do resíduo ao ligante asfáltico na região amazônica em função do grande volume de produção deste tipo de rejeito

\section{Materiais e métodos}

\subsection{Caracterização química do resíduo de cobre}

O resíduo sulfetado proveniente da mineração de cobre é oriundo da serra do Sossego situada no município de Canaã dos Carajás/PA e segundo Muller e Castro Filho (2008) a composição mineralógica e química do minério deste local é Feldspato (27\%), Quartzo (26\%), Clorita (14\%), Biotita (10\%), Magnetita (9\%), Carbonatos (6\%), Calcopirita (3\%), Anfibólio (2\%), Epidoto (2\%) e Hematita (1\%).

Os testes de lixiviação conduzidos em amostras de rejeito, por ocasião do Estudo de Impacto Ambiental da Mina do Sossego, indicaram concentrações muito baixas para metais lixiviados considerados significativos: Antimônio $(\mathrm{Sb}<10 \mathrm{ppm})$, Prata $(\mathrm{Ag}<3 \mathrm{ppm})$, cádmio $(\mathrm{Cd}<3 \mathrm{ppm})$, cobalto (Co $<40 \mathrm{ppm})$, Cromo $(\mathrm{Cr}<144 \mathrm{ppm})$, Chumbo $(\mathrm{Pb}<44 \mathrm{ppm})$ e Urânio (U<10 ppm).

ANBR 10004/2004 classifica este material proveniente da mineração do cobre sulfetado como um resíduo sólido, que resulta de atividade de origem industrial cujo lançamento na rede pública de esgoto se torna inviável. Segundo a mesma norma técnica o resíduo utilizado nesta pesquisa é o de nível II-B (inerte).

Na Malásia a composição química do resíduo de cobre varia, mas os principais óxidos presentes são óxido de silício, óxido de cálcio e óxido de alumínio. Outros incluem óxido de ferro, óxido de magnésio e óxido de enxofre. Os metais pesados notáveis presentes nos rejeitos de cobre são cobre, zinco e chumbo. Há também um traço de cromo e cádmio [10].

O resultado de lixiviação realizado com resíduo de cobre mostrou que a concentração dos metais pesados é 
inferior ao limite de referência estabelecido segundo a US EPA (United States Environmental Protection Agency). As concentrações dos metais pesados cobre $(\mathrm{Cu})$, Cromo $(\mathrm{Cr})$; Chumbo $(\mathrm{Pb})$, Cádmio (Cd) e o Níquel (Ni) detectadas são extremamente baixas e não excedem os limites. Além disso, verificou-se claramente a adição de betume ao resíduo não teve efeito sobre a lixiviação dos metais pesados. Isso indica que o uso do resíduo de cobre como material de mistura de asfalto não criaria risco imediato ou a longo prazo para o meio ambiente [11].

Pesquisas aplicaram o resíduo de cobre sulfetado em argamassas para a indústria de construção civil, a fim de reduzir o impacto sobre o meio ambiente na Região de Atacama, no Chile. A avaliação foi realizada por meio de comparação técnica entre argamassas preparadas com areia convencional e o resíduo [12].

A análise química quantitativa, mostrou a presença dos mesmos compostos químicos presentes na areia da região do Atacama, Chile, e o resíduo de cobre. O resultado mostrou ser inerte o resíduo de cobre. A análise química quantitativa da areia de rejeitos de cobre indicou a presença de: $\mathrm{SiO}_{2}(54,30 \%), \mathrm{FeO}(12,10 \%), \mathrm{Al}_{2} \mathrm{O}_{3}(9,21 \%), \mathrm{Fe}_{3} \mathrm{O}_{4}(3,60 \%)$ $\mathrm{MgO}(2,26 \%), \mathrm{S}(1,94 \%), \mathrm{CaO}(1,14 \%)$. Os compostos químicos são características do resíduo de cobre produzidos nas minas localizadas na região de Atacama.

\subsection{Análise granulométrica}

O resíduo de cobre sulfetado apresentou uma curva de distribuição de tamanho de partículas finas. Com o ensaio de granulometria foi traçada a curva, e calculados os parâmetros de dimensão máxima do agregado de $1,19 \mathrm{~mm}$ e módulo de finura de 0,87 . A Figura 1 apresenta a curva granulométrica do resíduo sulfetado de Canaã dos Carajás/PA e as curvas obtidas para o resíduo de cobre na Malásia [10-12].

O tamanho dos grãos do resíduo de cobre no Chile é fino (91\% passaram na peneira $0,315 \mathrm{~mm}$ e $55 \%$ passaram na peneira $0,16 \mathrm{~mm}$ ). Além disso, os rejeitos de apresentaram um módulo de finura de 0,54 [12].

A análise granulométrica para o resíduo de cobre explorado na Malásia mostra que mais de $75 \%$ dos rejeitos são menores do que $1 \mathrm{~mm}$, aproximadamente $73 \%$ dos rejeitos passaram na peneira de $1,18 \mathrm{~mm}$ e $8 \%$ do dos grãos foram retidos na peneira de $3,35 \mathrm{~mm}$, ou seja $92 \%$ passaram na peneira $3,35 \mathrm{~mm}[10]$.

\subsection{Caracterização do ligante}

Neste experimento foi utilizado um ligante asfáltico CAP 50/60 puro e mais duas amostras aditivadas com resíduo de cobre sulfetado passante na peneira $\mathrm{n}^{\circ} 200$ nas proporções de 2,5\% e 5,0\% em relação a massa de ligante. As mostras foram submetidas a estufa de filme fino rotativo (RTFOT) e os resultados de ensaios após envelhecimento foram comparados para avaliação das consequências do envelhecimento.

Para avaliar o efeito do envelhecimento a curto prazo foi necessário envelhecer as misturas pela técnica RTFOT (Rolling ThinFilmOven Test), onde 8 frascos com $35 \mathrm{~g}$ de CAP foram colocados horizontalmente em uma bandeja, sofrendo rotação de 15 r.p.m., formando um filme de CAP de espessura aproximada de $1,25 \mathrm{~mm}$, a $163^{\circ} \mathrm{C}$ por 85 minutos, este processo expõe todo o ligante ao calor e ao fluxo de ar de aproximadamente $4.000 \mathrm{~mL} / \mathrm{min}$, evitando assim a formação de película protetora, segundo o método ASTM 2872, conforme Figura 2.

Neste estudo reológico foram utilizadas amostras do CAP 50/70, com adições de $2,5 \%$ e $5,0 \%$ de resíduo passante na peneira $\mathrm{n}^{\circ} 200$, antes e após o envelhecimento.

As alterações reológicas foram acompanhadas em um Reômetro de Cisalhamento Dinâmico (DSR), quanto suas propriedades de módulo de complexo $\left(\mathrm{G}^{*}\right)$ e o ângulo de fase $(\delta)$. Com estes parâmetros foi possível definir o grau de desempenho das misturas (PG), segundo a classificação SuperPave, onde é obtida a temperatura imediatamente inferior a ao valor do parâmetro $\mathrm{G}^{*} / \mathrm{sen} \delta$ igual a 1,0 Kpa.

A partir do ensaio no DSR, foi possível também classificaro volume de tráfego, que o ligante pode resistir sem deformar, tendo como parâmetro o ensaio de Fluência e Recuperação sob Múltipla Tensão - MSCR, ASTM D7405-15. A especificação de Classificação AASHTO M 332-14 de ligante asfáltico em função do tráfego está apresentada. Os parâmetros analisados são comparados na Tabela 1:

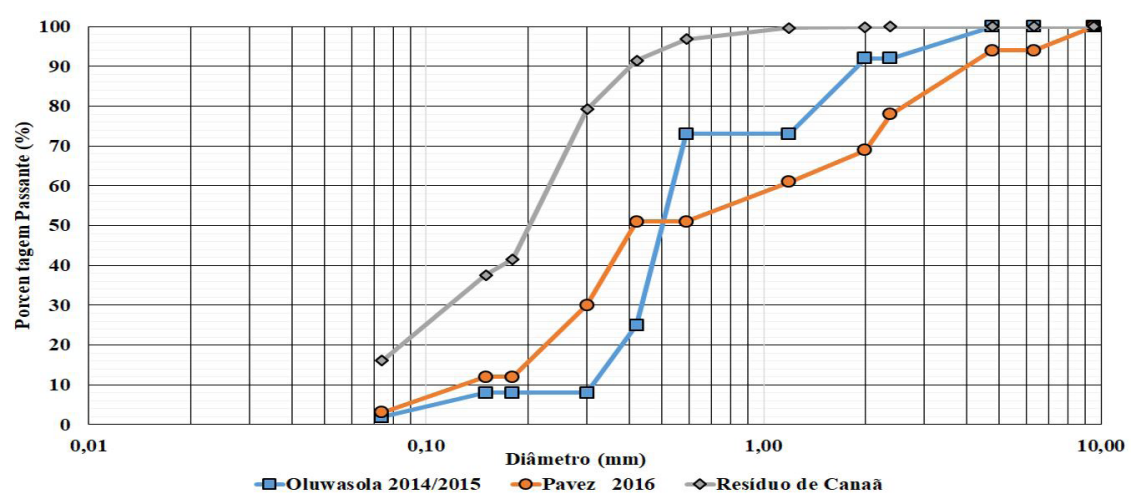

Figura 1. Curva granulométrica do resíduo de cobre na Malásia, Chile e Canaã dos Carajás/PA. 


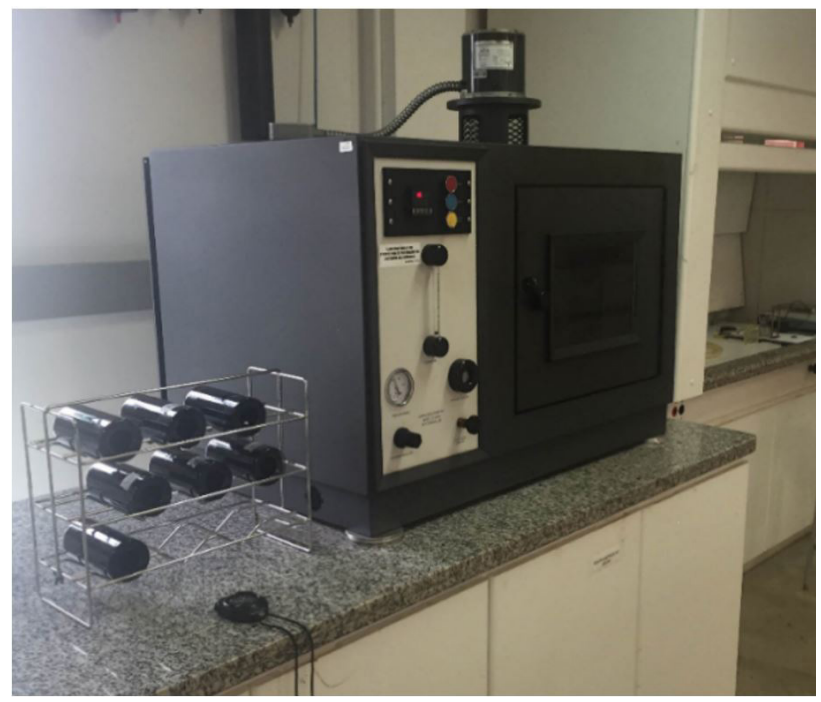

Figura 2. Equipamento utilizado para realização do ensaio RTFOT.

Tabela 1. Classificação AASHTO M 332-14 de ligante asfáltico em função do tráfego

\begin{tabular}{|c|c|c|c|}
\hline Parâmetro & Limites Jnr ${ }_{3200}$ & PG MSCR & Tráfego \\
\hline & $<4,5 \mathrm{KPa}^{-1}$ & $\begin{array}{l}\text { S - Tráfego } \\
\text { Padrão }\end{array}$ & $<10$ milhões \\
\hline $\mathrm{Jnr}_{3200} ; \mathrm{KPa}^{-1}$ & $<2,0 \mathrm{KPa}^{-1}$ & $\begin{array}{l}\text { H - Tráfego } \\
\text { Pesado }\end{array}$ & $\begin{array}{l}\text { De } 10 \text { a } 30 \\
\text { milhões }\end{array}$ \\
\hline \multirow[t]{2}{*}{$\mathrm{Jnr}_{\text {diff }}<0,75$} & $<1,0 \mathrm{KPa}^{-1}$ & $\begin{array}{l}\text { V-Tráfego } \\
\text { Muito Pesado }\end{array}$ & >30 milhões \\
\hline & $<0,5 \mathrm{KPa}^{-1}$ & $\begin{array}{c}\text { E - Tráfego } \\
\text { Extra Pesado }\end{array}$ & $\begin{array}{l}>30 \text { milhões e } \\
\text { tráfego parado }\end{array}$ \\
\hline
\end{tabular}

- Jnr - Compliância não recuperável: Potencial do material sofrer deformação permanente;

- Jn,diff - Sensibilidade do ligante a mudanças no nível de tensão.

\section{Apresentação e análise dos resultados}

Os ensaios reológicos foram executados no Laboratório de Geotecnia da COPPE/UFRJ. Para estes ensaios foi necessário envelhecer as misturas pela técnica RTFOT (Rolling Thin Film Oven Test), onde 8 frascos com $35 \mathrm{~g}$ de CAP são colocados horizontalmente em uma bandeja, sofrendo rotação de 15 r.p.m., formando uma camada de CAP de espessura aproximada de $1,25 \mathrm{~mm}$, a $163^{\circ} \mathrm{C}$ por 75 minutos, conforme Figura 3. Desta forma todo o ligante é exposto ao calor e ao fluxo de ar de aproximadamente $4.000 \mathrm{~mL} / \mathrm{min}$, evitando assim a formação de película protetora, segundo o método ASTM 2872 (2012).

Neste estudo reológico foram utilizadas amostras do CAP 50/70, com adições de $2,5 \%$ e $5,0 \%$ de resíduo passante na peneira $\mathrm{n}^{\circ} 200$, com e sem envelhecimento. As alterações reológicas foram acompanhadas em um Reômetro de Cisalhamento Dinâmico (DSR), quanto suas propriedades de módulo de complexo $\left(\mathrm{G}^{*}\right)$ e o ângulo de

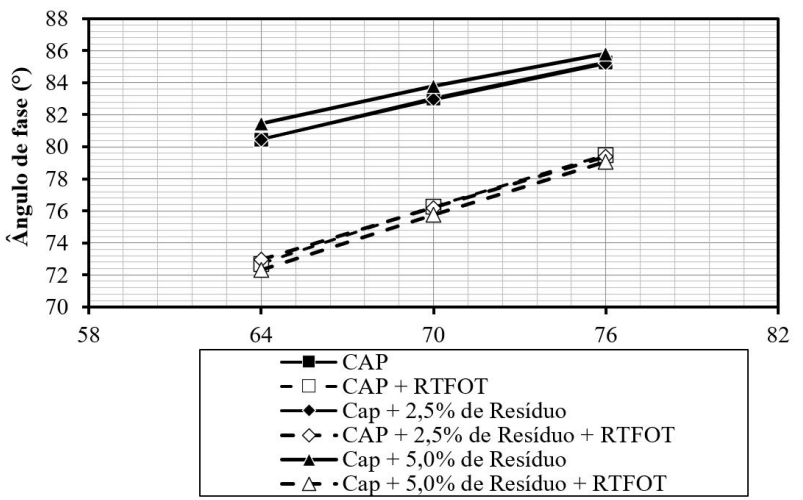

Figura 3. Ângulo de fase do ligante asfáltico em várias condições.

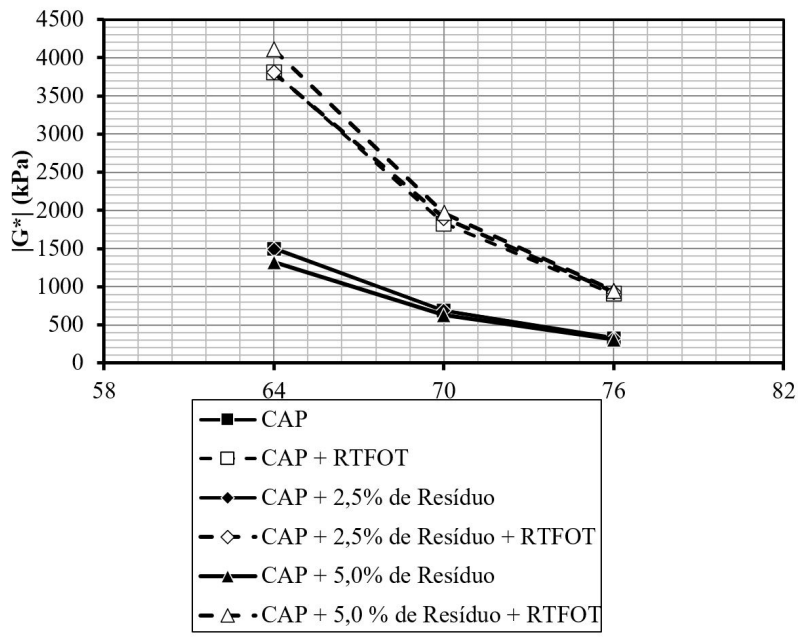

Figura 4. Módulo complexo do ligante asfáltico em várias condições.

fase $(\delta)$. Com estes parâmetros foi possível definir o grau de desempenho das misturas (PG), segundo a classificação SuperPav (ASTM D 6373-13 e AASHTO M320-10), onde é obtida a temperatura imediatamente inferior a ao valor do parâmetro $\mathrm{G}^{*} / \mathrm{sen} \delta$ igual a 1,0 Kpa, conforme a Figura 4.

A partir do ensaio no DSR, foi possível também classificar o volume de tráfego, que o ligante pode resistir sem deformar, tendo como parâmetro o ensaio de Fluência e Recuperação sob Múltipla Tensão-MSCR, ASTM D7405 - 15. A especificação de Classificação AASHTO M 332-14 de ligante asfáltico em função do tráfego está apresentada. Os parâmetros analisados são comparados na Tabela 2.

O CAP em análise pela classificação Superpave, foi caracterizado como um ligante PG 64 (64 - temperatura mais alta em que o ligante possui propriedades físicas adequadas para resistir à deformação permanente); não sofrendo alteração classificatória pela adição de $2,5 \%$ e $5,0 \%$, para conforme Figura 5.

Na Figura 6, pode-se notar a parcela de energia que foi transferida e armazenada pelo CAP, expressa pela grandeza do grau de desempenho (G'). Os dados mantêm o comportamento dos outros parâmetros reológicos até aqui tratados, com uma leve tendência de aumento para a adição de 5,0\% de resíduo e não demonstrando diferença significativa antes e depois do envelhecimento. 
Tabela 2. Resumo dos resultados da reologia do ligante asfáltico desta pesquisa

\begin{tabular}{ccccc}
\hline \multicolumn{5}{c}{ Amostras sem Envelhecimento } \\
\hline \multirow{2}{*}{ Amostras } & Temp. $\left({ }^{\circ} \mathbf{C}\right)$ & G*(Pa) & $\boldsymbol{\delta}\left({ }^{\circ}\right)$ & $\begin{array}{c}\text { G*/ } \\
\text { Sen } \boldsymbol{\delta}(\mathbf{P a})\end{array}$ \\
\hline CAP & 64 & $15,0 \times 10^{2}$ & 80,45 & $1,53 \times 10^{2}$ \\
& 70 & $6,88 \times 10^{2}$ & 83,01 & $6,93 \times 10^{2}$ \\
CAP + 2,5\% & 76 & $3,30 \times 10^{2}$ & 85,27 & $3,31 \times 10^{2}$ \\
de Resíduo & 70 & $14,9 \times 10^{2}$ & 80,45 & $1,51 \times 10^{2}$ \\
& 76 & $3,27 \times 10^{2}$ & 82,95 & $6,91 \times 10^{2}$ \\
CAP + 5,0\% & 64 & $13,2 \times 10^{2}$ & 81,46 & $1,34 \times 10^{2}$ \\
de Resíduo & 70 & $6,25 \times 10^{2}$ & 83,80 & $6,29 \times 10^{2}$ \\
& 76 & $3,11 \times 10^{2}$ & 85,79 & $3,12 \times 10^{2}$ \\
\hline \multirow{2}{*}{ Amostras } & Temp. $\left({ }^{\circ} \mathbf{C}\right)$ & $\mathbf{G} *(\mathbf{P a})$ & $\boldsymbol{\delta}\left({ }^{\circ}\right)$ & $\mathbf{G} * /$ \\
& 64 & $38,1 \times 10^{2}$ & 72,69 & $39,9 \times 10^{2}$ \\
\hline CAP & 70 & $18,3 \times 10^{2}$ & 76,28 & $18,9 \times 10^{2}$ \\
& 76 & $9,10 \times 10^{2}$ & 79,49 & $9,21 \times 10^{2}$ \\
CAP + 2,5\% & 64 & $38,1 \times 10^{2}$ & 72,97 & $39,8 \times 10^{2}$ \\
de Resíduo & 70 & $18,9 \times 10^{2}$ & 76,20 & $19,6 \times 10^{2}$ \\
& 76 & $9,28 \times 10^{2}$ & 79,38 & $9,45 \times 10^{2}$ \\
CAP + 5,0\% & 64 & $41,1 \times 10^{2}$ & 72,31 & $43,1 \times 10^{2}$ \\
de Resíduo & 70 & $19,6 \times 10^{2}$ & 75,78 & $20,2 \times 10^{2}$ \\
& 76 & $9,48 \times 10^{2}$ & 79,05 & $9,66 \times 10^{2}$ \\
\hline
\end{tabular}

Complementando a informação da Figura 6, a Figura 7 demonstra a parcela de energia que foi transferida de maneira irreversível às amostras, corroborando com os valores de G', onde as amostras aditivadas demonstraram o mesmo comportamento isonômico do grau de desempenho.

A tangente do ângulo de fase demonstra a sensibilidade a variações da composição do material, sendo expressa pela relação G"/G', e sua redução representa uma maior elasticidade do ligante, ou maior módulo elástico. Novamente, conforme Figura 8 , as amostras apresentaram uma tendência igualitária de comportamento.

A partir do ensaio de MSCR pôde-se obter a compliancia não recuperável (razão entre deformação não recuperável e a carga aplicada) a 3.200 Pa, e a diferença de percentual entre os valores de $\mathrm{J}_{\mathrm{nr}}$ a $100 \mathrm{~Pa}$ e $3.200 \mathrm{~Pa}\left(\mathrm{~J}_{\mathrm{nr} \text {, diff }}\right)$ não pode ser superior a $75 \%$, evitando que o ligante seja excessivamente sensível a variação de tensão.

Os resultados apontam que o volume de tráfego para os quais as amostras estão aptas, não apresentou diferença significativa, sendo classificado como tráfego padrão com suporte para um volume de 10 milhões de eixos padrões durante a vida de projeto, como pode-se se verificar na Tabela 3 e Figura 8.

A Figura 9 demonstra ainda que o resíduo não alterou a deformação específica das amostras, permanecendo os valores praticamente iguais ao longo do tempo do ensaio.
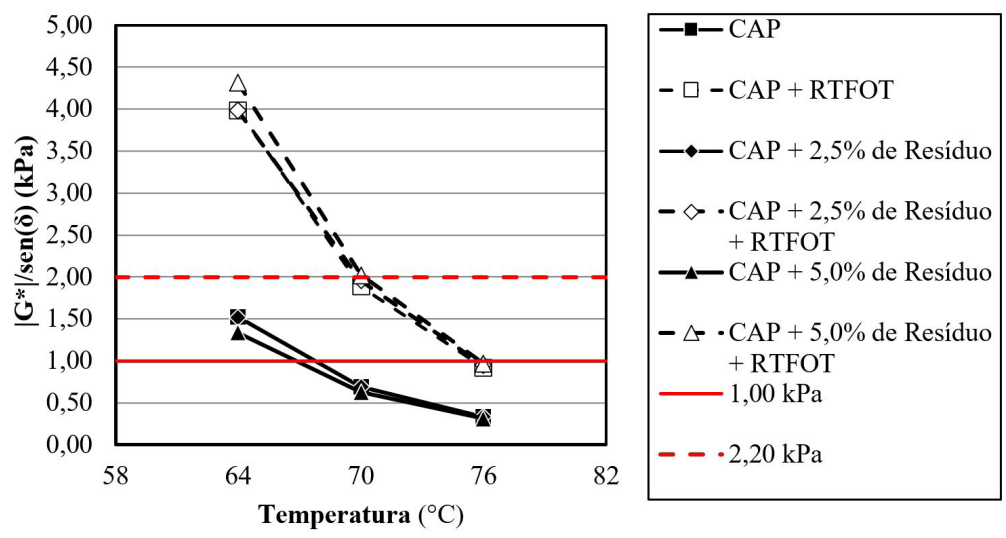

Figura 5. Grau de desempenho do ligante asfáltico em várias condições.

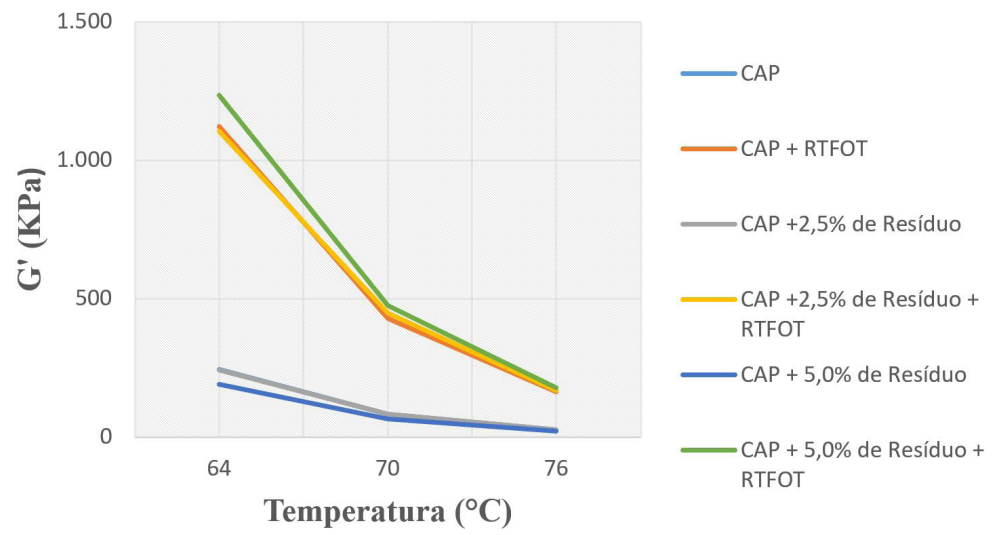

Figura 6. Grau de desempenho do ligante asfáltico em várias condições. 


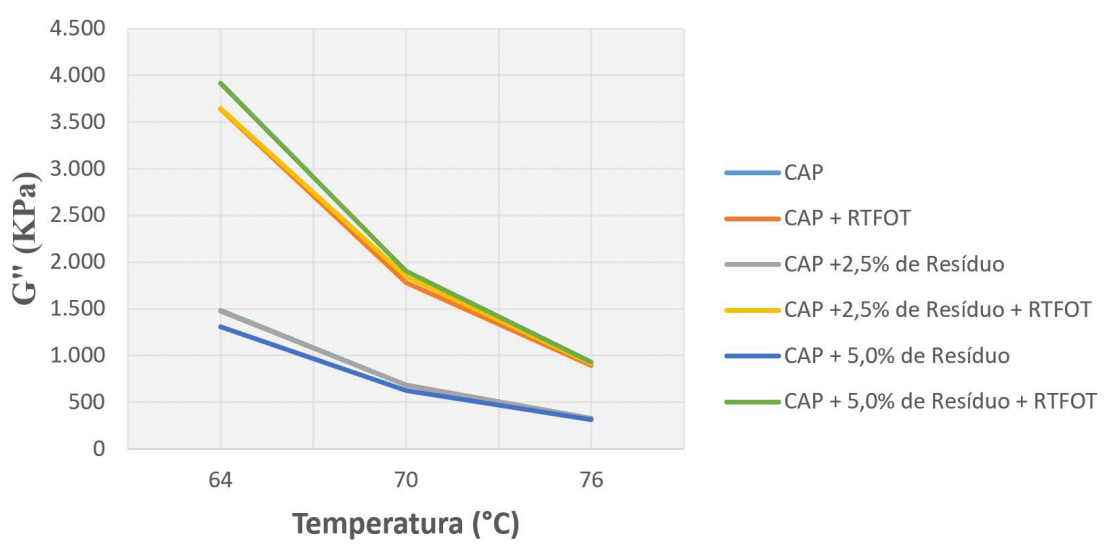

Figura 7. Módulo de perda do ligante asfáltico em várias condições.

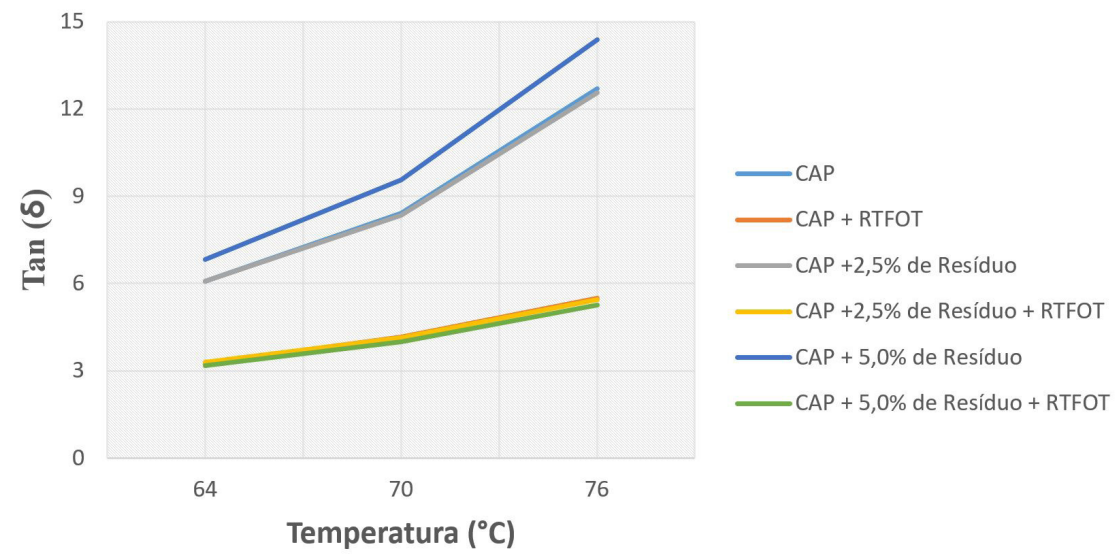

Figura 8. Tangente de $\delta$ do ligante asfáltico em várias condições.

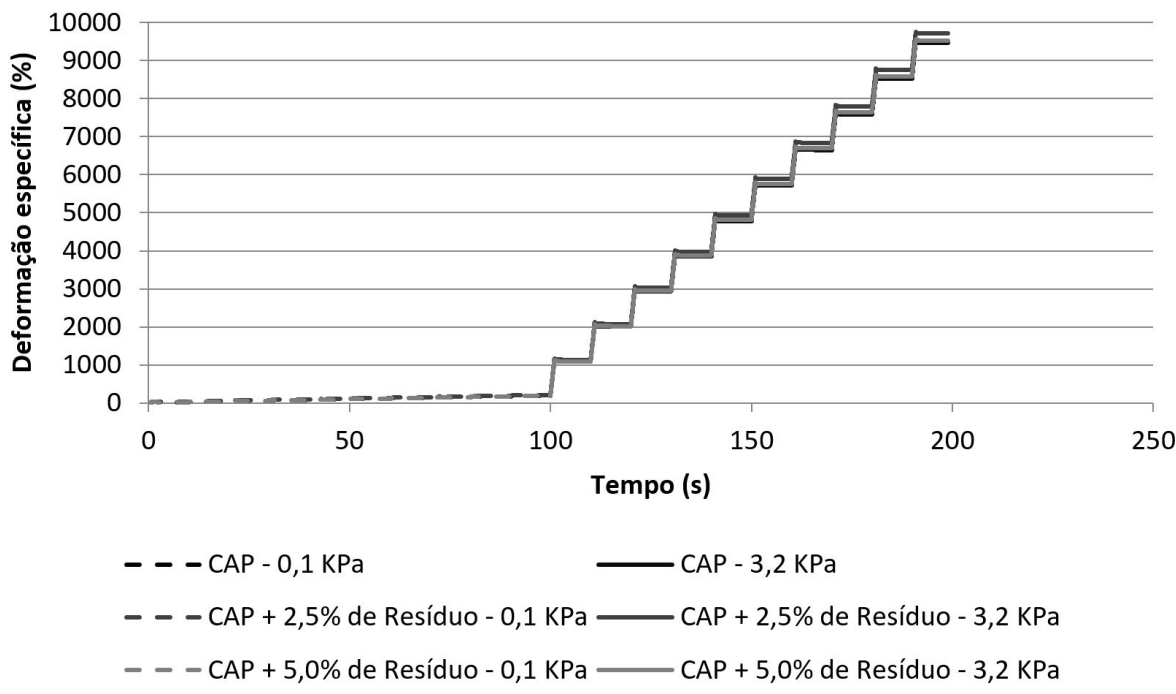

Figura 9. Curva do Ensaio MSCR do ligante asfáltico em várias condições.

Tabela 3. Resultado MSCR do ligante asfáltico desta pesquisa

\begin{tabular}{cccc}
\hline Parâmetro & CAP & $\begin{array}{c}\text { CAP+ 2,5\% } \\
\text { de Resíduo }\end{array}$ & $\begin{array}{c}\text { CAP+ 5,0\% } \\
\text { de Resíduo }\end{array}$ \\
\hline $\mathrm{Jnn} 3.200 \mathrm{~Pa}$ & 2,9 & 3,0 & 2,9 \\
$\mathrm{~J}_{\text {nrd,iff }}(\%)$ & $51 \%$ & $46 \%$ & $54 \%$ \\
\hline
\end{tabular}

\section{Conclusões}

Os ligantes asfálticos puros e adicionados com frações de resíduo forma submetidos ao envelhecimento a curto prazo na estufa RTFOT e posteriormente a ensaios reológicos antes a pós envelhecimento. 
Os ensaios reológicos demonstraram um comportamento semelhante entre as amostras de CAP, CAP $+2,5 \%$ de resíduo e $\mathrm{CAP}+5,0 \%$ de resíduo. A rigidez das misturas com 5,0\% de resíduo e submetidas ao envelhecimento apresentou uma leve tendência de aumento. O mesmo comportamento se deu com as amostras envelhecidas pelo método RTFOT.

Quanto a classificação SUPERPAVE, o ligante asfáltico não sofreu alteração de classificação pela presença do resíduo, mantendo sua classificação em PG 64.O ensaio de MSCR apontou para resistência ao tráfego padrão, com capacidade para suportar volume de 10 milhões de eixos padrões durante a vida de projeto, não apresentando diferença entre as amostras.
A partir destas conclusões, a pesquisa apontou para a viabilidade de utilização do resíduo da mineração do cobre sulfetado, segundo as características reológicas testadas neste artigo para o envelhecimento a curto prazo, pois de uma maneira geral as propriedades reológicas não apresentaram diferenças significativas com e sem resíduo, antes a pós envelhecimento.

O resultado promissor deste estudo e contribuições significativas na redução do uso dos recursos naturais, o resíduo do cobre sulfetado é material adequado ao uso de pavimento. Além de promover a sustentabilidade de recursos naturais e não renováveis, seu uso também reduzirá o custo da construção rodoviária e, ao mesmo tempo, preservará o meio ambiente.

\section{Referências}

1 Witczak MWE, Mirza MW. Development of global aging system for short and long term aging of asphalt cements. In: Proceedings of Asphalt Paving Technology; 1995; Portland, OR. St Paul, MN: Association of Asphalt Paving Technologists; 1995. (vol. 64).

2 Button JW. Permeability of asphalt surfasse seals and their effect on aging of underlying asphalt concrete. Transportation Research Record: Journal of the Transportation Research Board. 1996;1535(1):124-130.

3 Tonial IA, Motta LMG, Medina J, Souza AM. Características da fadiga e resiliencia de concretos asfálticos brasilieros. In: Anais da 33 ${ }^{\mathrm{a}}$ Reunião Anual de Pavimentação; 2001; Florianópolis, SC. Rio de Janeiro: ABPv; 2001.

4 Whiteoak D. (1990). Shell betumen handbook. Chertsey, UK: Shell; 1990.

5 Forte MM, Silva LS, Bartolomeu P, Durrieu F, Farcas F. Envelhecimentos UV de ligantes asfálticos. Revista Transportes. 2005;13(2):5-20.

6 Migliori F, Corté J-F. Comparative study of RTFOT and PAV ageing simulation laboratory tests. Transportation Research Record: Journal of the Transportation Research Board. 1998;1638(1):56-63.

7 Bahia H, Hanson D, Zeng M, Zhai H, Khatri ME, Anderson R. Characterization of modified asphalt binders in superpave mix design. Washington: National Academic Press; 2001. (NCHRP Report, no. 459).

8 Pará. Departamento Nacional de Produção Mineral - DNPN. Informe Mineral Pará. Belém; 2014.

9 Oluwasola EA, Hainin MR, Aziz MMA. Evaluation of asphalt mixtures incorporating electric arc furnace steel slag and copper mine tailings for road construction. Transportation Geotechnics. 2015;2:47-55.

10 Oluwasola EA, Hainin MR, Aziz MMA. Comparative evaluation of dense-graded and gap-graded asphalt mix incorporating electric arc furnace steel slag and copper mine tailings. Journal of Cleaner Production. 2016;122:315325.

11 Oluwasola EA, Hainin MR, Aziz MMA, Yaacob H, Warid MNM. Potentials of steel slag and copper mine tailings as construction materials. Materials Research Innovations. 2014;18(6):250-254.

12 Pavez O, González L, Veja H, Rojas E. Copper tailings in stucco mortars. International Engineering Journal. 2016;69(3):333-339.

Recebido em: 31 Ago. 2019

Aceito em: 25 Maio 2020 